\title{
'Cachaça' na tradução de obras literárias brasileiras para a língua inglesa
}

\author{
Rozane Rodrigues Rebechi*
}

\begin{abstract}
This paper aims at analyzing the strategies and implications of translation of the term 'cachaça' in English. From a literary corpus consisting of original texts in Portuguese and their translations into English, an Anglocentric tendency of domesticating the term was observed, with choices of 'equivalents' which lead to mischaracterization of that Brazilian cultural marker and also reduce the sense of foreignness to the English-language reader.
\end{abstract}

Keywords: cultural translation; anglocentrism; cachaça.

Resumo: O objetivo deste artigo foi analisar as estratégias e as implicações da tradução do termo 'cachaça' em língua inglesa. A partir de um corpus literário formado por originais em língua portuguesa e suas respectivas traduções em inglês, observou-se uma tendência anglocêntrica de domesticação do termo, por meio de escolhas de 'equivalentes' que acarretam descaracterização dessa marca cultural brasileira, além de diminuição do estranhamento por parte do leitor estrangeiro.

Palavras-chave: tradução cultural; anglocentrismo; cachaça.

\section{Introdução}

Como toda tentativa distorce o original, a tradução perfeita é impossível. Será tarefa do tradutor fazer com que essa impossibilidade pareça desaparecer, produzindo um texto que flua sem esforço na língua de chegada, sem apresentar problemas de compreensão, ou deve o tradutor encontrar uma forma de fazer o leitor compartilhar a sensação de estranhamento do que está lendo e, portanto, o muito da

\footnotetext{
* Doutoranda em Estudos Linguísticos e Literários em Inglês pela FFLCH-USP, bolsista FAPESP (2012/ 19609-0). Email: rozanereb@gmail.com.
} 
REBECHI, R. R. 'Cachaça' na tradução de obras literárias brasileiras

para a língua inglesa

realidade do texto desconhecido, sua língua, e seu mundo? (WHITE 1995: 333). ${ }^{1}$

O impasse do tradutor entre produzir um texto que busque a fluidez ou que mantenha no leitor estrangeiro um estranhamento do original tem permeado as discussões em torno do que seja uma tradução desejável talvez desde o início do século XIX, com o ensaio de SchleiermaCher (1813). Desde então, vários autores têm abordado essa dicotomia da tradução, entre eles: VenUtI (1995; 1998; 2005), com os conceitos de 'domesticação' e 'estrangeirização'; HSIA (2008), que também levanta a questão da dúvida do tradutor entre transmitir conceitos equivalentes (1) criando neologismos, correndo o risco da ininteligibilidade, ou (2) adotando termos familiares à cultura de chegada, perdendo, talvez, o significado do original; e PYM (1997), para quem a melhor das estratégias seria fazer o leitor 'viajar', por meio de uma tradução que o fizesse sentir o estranhamento do texto estrangeiro. Todos esses questionamentos demonstram a impossibilidade de uma tradução 'perfeita', que mantivesse todos os aspectos do texto original. Sempre haverá alguma perda, seja a da fluidez ou a do estranhamento.

Apesar de não existir consenso sobre o que seja uma tradução 'ética' (aliás, existem inúmeras definições de 'ética', como pode ser verificado, por exemplo, em de La Taille, 2006), muito tem sido discutido sobre a ética do tradutor, uma vez que suas escolhas, tomadas a partir de suas posições linguísticas, ideológicas e culturais, influenciam no processo de comunicação (cf. Pym, 1997; Venuti, 2005; Hatim \& Mason, 1997). Para esta pesquisa, tomaremos como base, principalmente, as ideias de VENUTI (2005), que é

\footnotetext{
${ }^{1}$ Because every attempt distorts the original, perfect translation is impossible. Is it the task of the translator to make this impossibility seem to disappear, to produce a text that flows effortlessly in the new language, presenting no problems of understanding, or should the translator somehow find a way to bring the reader to share a sense of the foreignness of what he is reading, and hence this much of the reality of the unknown text, its language, and its world?

${ }^{2}$ As traduções neste artigo são de autoria da autora do trabalho.
} 
REBECHI, R. R. 'Cachaça' na tradução de obras literárias brasileiras

para a língua inglesa

favorável à introdução de palavras da cultura de partida na cultura de chegada, produzindo no leitor uma sensação de distanciamento ou estranhamento em relação ao original.

Para Venuti (2005), a tradução pode ser considerada um "ato de violência" contra uma nação apenas pelo fato de esta ser entendida como possuidora de uma identidade nacional homogênea, que seria "ameaçada" pelas diferenças culturais e linguísticas do texto estrangeiro (p. 177-178). Naturalmente, a recepção do texto estrangeiro não se dá sempre da mesma forma. Culturas diferentes tendem a adotar diferentes estratégias de tradução, e estas não são escolhidas por acaso. Neste artigo, serão analisadas escolhas adotadas na tradução de 'cachaça' para a língua inglesa e suas implicações para a construção da identidade brasileira aos olhos do estrangeiro.

\section{A tradução de 'cachaça' em obras literárias}

Uma das manifestações culturais mais fortes de um povo é sua culinária, tanto assim que o antropólogo LÉvi-STRAuss (2007) a coloca ao lado da linguagem em grau de importância: "Assim como a linguagem, a culinária é uma forma verdadeiramente universal de atividade humana: assim como não existe sociedade sem linguagem, não existe sociedade que, de alguma forma, não cozinhe os alimentos" (p. 28) ${ }^{3}$. Como forte aspecto cultural, a culinária tem papel constante - muitas vezes até central - em textos literários. É 0 caso, por exemplo, de D. Flor e Seus Dois Maridos (AmAdo 1971). A tradução para a língua inglesa de alguns elementos da culinária baiana presentes na obra foi analisada em CoRRÊA et al (2003), a fim de "detectar possíveis

\footnotetext{
${ }^{3}$ [Cooking] is with language a truly universal form of human activity: if there is no society without a language, nor is there any which does not cook in some manner at least some of its food.
} 
REBECHI, R. R. 'Cachaça' na tradução de obras literárias brasileiras

para a língua inglesa

alterações que venham a deturpar o percurso histórico-antropológico-cultural da constituição de nosso povo, tão facilmente perceptível através da culinária" (p. 54). As autoras concluíram que houve preferência pelas seguintes estratégias de tradução: adaptação de pratos e ingredientes, explicitação do prato e substituição de ingredientes (por exemplo, a troca de 'azeite-de-dendê' por olive oil [azeite de oliva]). Essas escolhas teriam resultado em uma "imagem distorcida" da especificidade da culinária baiana, uma vez que pratos semelhantes na composição dos ingredientes receberam, muitas vezes, a mesma tradução/definição. Foi o caso, por exemplo, de 'abará' e 'acarajé', que foram traduzidos genericamente como bean fritters (bolinho de feijão), enquanto 'moqueca' se tornou fried fish vinaigrette (peixe frito ao vinagrete).

De fato, a grande diversidade das cozinhas regionais brasileiras, constituídas tradicionalmente a partir de um amálgama das influências indígena, portuguesa e africana, e posteriormente acrescidas de elementos italianos, espanhóis, árabes etc., se revela um desafio até mesmo para 0 próprio brasileiro. Essa dificuldade se intensifica na tradução para o inglês, mesmo porque não há sequer uma obra terminográfica bilíngue que se proponha a oferecer tradução e/ ou definição para os termos da culinária típica brasileira. Portanto, a fim de analisar a tradução para a língua inglesa de um elemento menos regionalista, neste estudo serão analisadas as estratégias de tradução de 'cachaça', que, assim como 0 arroz e o feijão, também está presente no Brasil inteiro. Aliás, é provável que essa bebida, ingrediente indispensável da mundialmente conhecida 'caipirinha', seja o elemento da culinária brasileira mais reconhecido pelos estrangeiros.

Com uma pesquisa do termo 'cachaça' no Compara ${ }^{4}$, corpus paralelo (textos originais com suas respectivas traduções) formado por textos

\footnotetext{
${ }^{4}$ o COMPARA é um corpus paralelo que tem como base uma coleção de textos literários originais com suas respectivas traduções no par de línguas português e inglês. 0 acesso é gratuito pelo site: www. linguateca. pt/ COMPARA/.
} 
REBECHI, R. R. 'Cachaça' na tradução de obras literárias brasileiras

para a língua inglesa

literários, verificou-se que, das obras da literatura brasileira disponíveis no corpus, pelo menos cinco citam essa bebida ${ }^{5}$. São elas: 0 Mulato (AzEvedo 1881), O Cortiço (AzeVedo 1890), Os Sinos da Agonia (Dourado 1975), Memórias de um Gigolô (REY 1986) e O Xangô de Baker Street (SOARES 1995). Na Tabela 1 são mostrados os excertos originais, alinhados com suas respectivas traduções em língua inglesa (as ênfases são da autora deste artigo):

\begin{tabular}{|c|c|c|c|c|}
\hline OBRA & ORIGINAL & TRADUÇĀO & ORIGINAL & TRADUÇĀO \\
\hline O Mulato & 1881 & 1990 & $\begin{array}{l}\text { O leiloeiro tinha } \\
\text { piscos d'olhos } \\
\text { significativos; de } \\
\text { martelo em punho, } \\
\text { entusiasmado, o ar } \\
\text { trágico, mostrava } \\
\text { com o braço erguido } \\
\text { um cálice de } \\
\text { cachaça, ou, } \\
\text { comicamente } \\
\text { acocorado -- } \\
\text { esbrocava com o } \\
\text { furador os paneiros } \\
\text { de farinha e de } \\
\text { milho. }\end{array}$ & $\begin{array}{l}\text { The auctioneer winked his } \\
\text { eyes meaningfully; excited, } \\
\text { with the gavel always in one } \\
\text { fist, his countenance serious, } \\
\text { he would raise his arm to } \\
\text { display a jug of crude } \\
\text { brandy, or squat comically } \\
\text { to poke at the baskets of } \\
\text { flour and corn with a sharp- } \\
\text { pointed rod. }\end{array}$ \\
\hline O Mulato & 1881 & 1990 & $\begin{array}{l}\text { Adorava os perfumes } \\
\text { ativos, as jóias e as } \\
\text { cores vivas; para ele, } \\
\text { nada havia, porém, } \\
\text { como um passeio ao } \\
\text { sítio, embarcado à } \\
\text { fresca da madrugada, }\end{array}$ & $\begin{array}{l}\text { He adored strong colognes, } \\
\text { jewels, and lively colors. But } \\
\text { there was nothing, in his } \\
\text { view, equal to a short trip } \\
\text { out to his rural property. He } \\
\text { would set off in the fresh } \\
\text { early morning, swigging }\end{array}$ \\
\hline
\end{tabular}

\footnotetext{
${ }^{5}$ Apenas um terço de cada obra é disponibilizado pelo Compara. Portanto, é possível que haja a ocorrência do termo em outras obras ou mesmo em outros trechos das obras analisadas aqui.
} 
REBECHI, R. R. 'Cachaça' na tradução de obras literárias brasileiras

para a língua inglesa

\begin{tabular}{|c|c|c|c|c|}
\hline & & & $\begin{array}{l}\text { bebericando o seu } \\
\text { trago de cachaça e } \\
\text { pitando o seu fumo } \\
\text { do Codó. }\end{array}$ & $\begin{array}{l}\text { gulps of sugarcane brandy } \\
\text { and smoking his Codó } \\
\text { mixture. }\end{array}$ \\
\hline O Cortiço & 1890 & 2000 & $\begin{array}{l}\text { Afinal, já Ihe não } \\
\text { bastava sortir o seu } \\
\text { estabelecimento nos } \\
\text { armazéns } \\
\text { fornecedores; } \\
\text { começou a receber } \\
\text { alguns gêneros } \\
\text { diretamente da } \\
\text { Europa: o vinho, por } \\
\text { exemplo, que ele } \\
\text { dantes comprava aos } \\
\text { quintos nas casas de } \\
\text { atacado, vinha-Ihe } \\
\text { agora de Portugal às } \\
\text { pipas, e de cada uma } \\
\text { fazia três com água e } \\
\text { cachaça; e } \\
\text { despachava faturas } \\
\text { de barris de } \\
\text { manteiga, de caixas } \\
\text { de conserva, caixões } \\
\text { de fósforos, azeite, } \\
\text { queijos, louça e } \\
\text { muitas outras } \\
\text { mercadorias. }\end{array}$ & $\begin{array}{l}\text { After a while, he began to } \\
\text { buy less from wholesalers } \\
\text { and ordered some products } \\
\text { directly from Europe -- wine, } \\
\text { for example. Before, he had } \\
\text { purchased it in demijohns, } \\
\text { but now he bought barrels } \\
\text { straight from Portugal. He } \\
\text { turned each barrel into } \\
\text { three by adding water and } \\
\text { rum. Likewise, he ordered } \\
\text { kegs of butter, crates of } \\
\text { canned goods, big boxes of } \\
\text { matches, oil, cheese, } \\
\text { crockery, and much else } \\
\text { besides. }\end{array}$ \\
\hline $\begin{array}{l}\text { Os Sinos da } \\
\text { Agonia }\end{array}$ & 1975 & 1988 & $\begin{array}{l}\text { Apesar da ordem } \\
\text { para que as vendas se } \\
\text { mantivessem } \\
\text { fechadas, muita } \\
\text { gente fizera de } \\
\text { véspera a sua }\end{array}$ & $\begin{array}{l}\text { Despite an order that the } \\
\text { stores should stay closed, } \\
\text { many people had stocked up } \\
\text { with spirits and baccy the } \\
\text { day before, and the drink } \\
\text { was running freely, drunk }\end{array}$ \\
\hline
\end{tabular}


REBECHI, R. R. 'Cachaça' na tradução de obras literárias brasileiras

para a língua inglesa

\begin{tabular}{|c|c|c|c|c|}
\hline & & & $\begin{array}{l}\text { provisão de cachaça } \\
\text { e patifaria, e cana } \\
\text { corria alegre, bebida } \\
\text { mesmo na boca da } \\
\text { botija, no bafo e no } \\
\text { arroto. }\end{array}$ & $\begin{array}{l}\text { straight from the bottle, } \\
\text { accompanied by burps and } \\
\text { stinking breath. }\end{array}$ \\
\hline $\begin{array}{l}\text { Os Sinos da } \\
\text { Agonia }\end{array}$ & 1975 & 1988 & $\begin{array}{l}\text { J anuário tirou a rolha } \\
\text { de sabugo com os } \\
\text { dentes, deixou a } \\
\text { cachaça cair quente } \\
\text { goela abaixo. }\end{array}$ & $\begin{array}{l}\text { J anuario pulled the corn-cob } \\
\text { stopper out with his teeth } \\
\text { and poured the spirit hot } \\
\text { down his throat. }\end{array}$ \\
\hline $\begin{array}{l}\text { O Xangô de } \\
\text { Baker } \\
\text { Street }\end{array}$ & 1995 & 1997 & $\begin{array}{l}\text {-- Se me permite, } \\
\text { senhor Holmes, o } \\
\text { melhor remédio para } \\
\text { esta sensação } \\
\text { matutina é uma boa } \\
\text { cachaça. }\end{array}$ & $\begin{array}{l}\text { "If you'll permit me, Mr. } \\
\text { Holmes, the best medicine } \\
\text { for this morning-after } \\
\text { sensation is a good dose of } \\
\text { cachaça." }\end{array}$ \\
\hline $\begin{array}{l}\text { O Xangô de } \\
\text { Baker } \\
\text { Street }\end{array}$ & 1995 & 1997 & -- Cachaça? & "Cachaça?" \\
\hline $\begin{array}{l}\text { O Xangô de } \\
\text { Baker } \\
\text { Street }\end{array}$ & 1995 & 1997 & $\begin{array}{l}\text {-- Saraiva, não sei se } \\
\text { é aconselhável dar } \\
\text { cachaça ao senhor } \\
\text { Holmes a esta hora -- } \\
\text { adiantou Mello } \\
\text { Pimenta, com } \\
\text { prudência. }\end{array}$ & $\begin{array}{l}\text { "Saraiva, I don't know if it's a } \\
\text { good idea to give Holmes } \\
\text { cachaça at this hour," } \\
\text { injected Mello Pimenta. }\end{array}$ \\
\hline $\begin{array}{l}\text { O Xangô de } \\
\text { Baker } \\
\text { Street }\end{array}$ & 1995 & 1997 & $\begin{array}{l}\text {-- Não é ele, é a } \\
\text { pomba-gira pedindo } \\
\text { cachaça, charuto e } \\
\text { velas -- explicou } \\
\text { Mukumbe. }\end{array}$ & $\begin{array}{l}\text { "It's not he, it's the pomba- } \\
\text { gira asking for rum, a cigar, } \\
\text { and candles," explained } \\
\text { Mukumbe. }\end{array}$ \\
\hline
\end{tabular}


REBECHI, R. R. 'Cachaça' na tradução de obras literárias brasileiras para a língua inglesa

\begin{tabular}{|l|l|l|l|l|}
\hline $\begin{array}{l}\text { O Xangô de } \\
\text { Baker } \\
\text { Street }\end{array}$ & 1995 & 1997 & $\begin{array}{l}\text { Watson emborcou } \\
\text { outra garrafa de } \\
\text { cachaça e desandou } \\
\text { a rir. }\end{array}$ & $\begin{array}{l}\text { Watson gulped another } \\
\text { bottle of rum and burst into } \\
\text { laughter. }\end{array}$ \\
\hline $\begin{array}{l}\text { Memórias } \\
\text { de um } \\
\text { Gigolô }\end{array}$ & 1986 & 1987 & $\begin{array}{l}\text { Um ano depois da } \\
\text { tragédia, eu } \\
\text { substituía o uísque } \\
\text { pelo finalô, } \\
\text { imediatamente } \\
\text { substituído pelo gim } \\
\text { e mesmo pela } \\
\text { cachaça com limão. }\end{array}$ & $\begin{array}{l}\text { A year after the tragedy, I } \\
\text { had replaced whiskey with } \\
\text { brandy and water, which was } \\
\text { immediately supplanted by } \\
\text { gin, and then by sugarcane } \\
\text { rum with lime. }\end{array}$ \\
\hline
\end{tabular}
respectivas traduções em inglês.

Apesar de terem sido escritas originalmente dentro de um período de mais de 100 anos (de 1881 a 1995), as cinco obras analisadas tiveram suas traduções publicadas em língua inglesa entre 1987 e 2000. Mesmo dentro desse curto espaço de tempo, são observadas várias mudanças nas estratégias de tradução do termo 'cachaça', até mesmo dentro de uma mesma obra.

Em 1990, o tradutor de 0 Mulato traduziu 'cachaça' como brandy, nome dado ao conhaque (cognac) produzido fora da região homônima na França. Brandy, ou brande - decalque já dicionarizado em língua portuguesa é uma bebida de alto teor alcoólico, em geral resultante da destilação do vinho, o que the confere uma cor de caramelo. Além da diferença de matériaprima, o brande é normalmente degustado após as refeições, enquanto a cachaça costuma ser servida em pequenas doses para 'abrir o apetite'.

Subproduto da atividade açucareira que remonta ao início da colonização, a cachaça foi, por muito tempo, considerada como popular e acessível, até mesmo marginalizada, sempre associada às camadas mais pobres da população. Somente nas últimas décadas, atingindo 
REBECHI, R. R. 'Cachaça' na tradução de obras literárias brasileiras para a língua inglesa

reconhecimento também dos estrangeiros, alguns alambiques passaram a utilizar processos mais refinados de produção e envelhecimento, e a bebida passou a transitar por todas as camadas sociais. Talvez como forma de amenizar a sofisticação do brandy, preservando, assim, a rusticidade da bebida no texto original, o tradutor tenha acrescentado ao 'equivalente' 0 adjetivo crude. Já em outra passagem, o tradutor optou por sugarcane brandy. De fato, existem variações de brandes, que podem ser destilados a partir dos sucos de maçã, damasco, pêssego, ameixa, cereja e até mesmo flores. Porém, uma pesquisa realizada em sites da Internet revela que todas as ocorrências de sugarcane brandy se referem exclusivamente à cachaça e não ao rum, por exemplo, que também é produzido a partir da cana de açúcar. Ou seja, parece que se cunhou o termo sugarcane brandy como equivalente em língua inglesa para 'cachaça'.

No trecho da obra o Cortiço disponibilizado pelo Compara, a única ocorrência de 'cachaça' foi traduzida em 2000 por rum. Nos dicionários Cambridge (1995) e Macmillan (2002), rum é simplesmente definido como "bebida forte feita de cana de açúcar". Essa definição também poderia se aplicar perfeitamente a 'cachaça', que também é feita a partir da cana de açúcar e é forte. Porém, apesar das semelhanças, o que diferencia as duas bebidas é o processo de fabricação. Enquanto o rum é obtido a partir da fermentação do melaço, e sua posterior destilação, a cachaça é resultado da fermentação da garapa. Além disso, talvez até hoje, a associação estereotipada do rum com piratas caribenhos, estimulada pela ficção, ainda povoe o imaginário, principalmente, daqueles pertencentes às velhas gerações. Naturalmente, a criatividade brasileira ajudou a popularizar a bebida utilizando-a até mesmo no lugar da cachaça, criando a 'caipiríssima', assim como fez com a vodka, na 'caipiroska', e até com o saquê, na 'saquerinha', versões da popular 'caipirinha'. Ainda assim, não é possível dissociar essas bebidas de seus lugares de origem. 
REBECHI, R. R. 'Cachaça' na tradução de obras literárias brasileiras

para a língua inglesa

Termo mais genérico para se referir a qualquer bebida alcoólica forte, spirit(s) foi a escolha do tradutor de Os Sinos da Agonia em 1988. Já o tradutor de 0 Xangô de Baker Street, livro que recebeu tradução para a língua inglesa apenas dois anos após ter sido escrito, lançou mão de três diferentes estratégias para as seis ocorrências de 'cachaça' localizadas pelo Compara. 0 empréstimo foi opção nas três passagens que, na ficção de Jô Soares, explicam a invenção da 'caipirinha'. Já durante um ritual de Candomblé, em que o personagem Watson teria incorporado a entidade pomba-gira, a opção do tradutor foi por rum. Vale salientar que a cachaça era oferecida aos escravos brasileiros a fim de dar-Ihes mais força para o trabalho pesado, e passou a ter papel importante em cerimônias religiosas de cultos afrobrasileiros. Em Memórias de um Gigolô, o mesmo tradutor de 0 Xangô de Baker Street optou por traduzir 'cachaça' como sugarcane rum - um pleonasmo, visto que todo rum é feito de cana de açúcar.

A associação da cachaça com o rum vai muito além da tradução literária. A descaracterização do produto brasileiro no exterior começa já no processo de importação/ exportação do produto para os Estados Unidos. Para fins de exportação, a bebida tipicamente brasileira só podia ser exportada para os Estados Unidos se apresentasse no rótulo o termo Brazilian Rum, restrição contra a qual o Ministério das Relações Exteriores vinha lutando, uma vez que os impostos que incidem sobre o rum são muito altos (cf. COSTA, 2006). Finalmente, em abril de 2012 foi assinado um acordo comercial entre Brasil e Estados Unidos que concede certificação fiscal para a cachaça como bebida de produção exclusivamente brasileira.

Ao analisar as soluções encontradas pelos tradutores para lidar com palavras culturalmente marcadas, AUBERT (1998) conclui que "os tradutores certamente buscam desenvolver soluções, por mais ad hoc que sejam, como opção preferida à de simplesmente eliminar as excentricidades culturais", pois acredita que seja "exatamente a natureza exótica dos textos e do que têm a relatar que constitui um chamariz para os leitores e se torna, portanto, 
REBECHI, R. R. 'Cachaça' na tradução de obras literárias brasileiras

para a língua inglesa

uma das principais motivações para executar-se a sua tradução" (p. 122). No entanto, em vários dos exemplos citados, a marca cultural brasileira representada por 'cachaça' se perdeu nas traduções que domesticaram 0 texto original, neutralizando o estranhamento que causaria no leitor de língua inglesa. Essas escolhas acarretam 0 apagamento da marca cultural representada por 'cachaça', uma bebida tipicamente brasileira que carrega consigo uma história que remonta à colonização do Brasil.

\section{Estrangeirização X domesticação}

Conforme mencionado anteriormente, a inexistência de obras terminográficas bilíngues português-inglês na área da culinária típica brasileira ajuda a disseminar os problemas de tradução. Entre esses problemas, podemos mencionar 'equivalentes' equivocados, definições incorretas, falta de padronização, erros ortográficos etc. (cf. REBECHI 2010). No entanto, a tradução, muito além da noção de equivalência terminológica, envolve questões culturais e representações (nem sempre éticas) da cultura de partida (cf. VENUTI 1998).

Diferentemente de outros elementos da culinária típica brasileira, o termo 'cachaça' já possui entrada em dicionários de língua inglesa, como, por exemplo, no American Heritage (desde a terceira edição, de 1992), ainda que a definição apresentada não seja muito esclarecedora ("a Brazilian white rum made from sugarcane"), pois, além de considerar 'cachaça' como um tipo de rum, pode levar erroneamente o consulente à conclusão de que o verdadeiro rum não seja feito de cana de açúcar. Mas, a dicionarização do termo em língua inglesa não o privou das escolhas domesticadoras feitas pelos tradutores.

O domínio econômico norte-americano que perdura há mais de um século acaba impondo o inglês como língua hegemônica. A consequência dessa 
REBECHI, R. R. 'Cachaça' na tradução de obras literárias brasileiras

para a língua inglesa

tendência, a que VENUTI (2005) denomina 'anglocêntrica', são as traduções domesticadoras, em que o leitor é subestimado pelo tradutor, e este toma para si o dever de transmitir algo da cultura dominada que só ele conseguiria explicar (cf. MelLo \& Vollet 2000).

Apesar de a tradução ser considerada como a prática que comunica o "espírito universal", superando as fronteiras entre línguas e culturas, Venuti (2005) questiona as diferenças linguísticas e culturais que influenciam as escolhas do tradutor e "complicam o processo comunicativo", uma vez que esse "universalismo" pode acabar eliminando as diferenças linguísticas e culturais, estas que são formadoras das identidades nacionais. Afirma, portanto, que uma tradução tem uma função nacionalista que independe da "intenção consciente do tradutor" (p. 179-181), e não se resume a uma atividade neutra. Afinal, conforme afirmam Hatim \& Mason (1997), o tradutor carrega consigo toda uma visão ideológica compartilhada pelo grupo a que pertence.

As estratégias de tradução de 'cachaça' nos trechos analisados evidencia a predominância de escolhas de termos mais familiares aos falantes de língua inglesa: crude/ sugarcane brandy, spirit(s) e (sugarcane) rum. Para Venuti (2005), essas escolhas visam aumentar a inteligibilidade dos leitores, criando uma "ilusão de transparência" ao fazer com que sintam como se estivessem lendo o original e não o texto traduzido. Nos exemplos mencionados, o tradutor poderia perfeitamente ter optado por uma prática mais estrangeirizadora, que mantivesse 0 estranhamento do termo original ('cachaça'), uma vez que esse não possui equivalente apropriado em língua inglesa.

Naturalmente, por mais domesticador que seja, o texto traduzido jamais conseguirá apagar todas as marcas culturais do texto de partida. A tradução colabora para a formação de identidades nacionais não só pelas estratégias usadas, mas também pela seleção dos textos a serem traduzidos (VENUTI 2005): 
REBECHI, R. R. 'Cachaça' na tradução de obras literárias brasileiras

para a língua inglesa

Embora as estratégias discursivas etnocêntricas possam dotar uma tradução com um efeito nacionalista, elas nunca conseguem remover por completo o estranhamento do texto estrangeiro. A diferença será comunicada por meio de outros níveis textuais, tanto formais quanto temáticos, na medida em que desviam sensivelmente de obras e tradições culturais na língua receptora (VENUTI 2005: 186) ${ }^{6}$.

Essa ideia é compartilhada por BURKE (2008), que afirma que a tradução revela com clareza o que uma cultura considera interessante em outra, por meio da escolha de textos que carregam conceitos formadores de uma identidade nacional. A própria seleção dos livros a serem traduzidos revela a preferência pelo estranho, diferente. Em relação aos livros que serviram como base para a análise da tradução do termo 'cachaça', é possível observar um interesse crescente pela tradução da literatura brasileira em língua inglesa. Enquanto levou mais de 100 anos para as obras escritas originalmente no século XIX ( $O$ Mulato e $O$ Cortiço) serem traduzidas, aquelas publicadas a partir da década de 1970 no Brasil (Os Sinos da Agonia, Memórias de um Gigolô e 0 Xangô de Baker Street) receberam tradução em língua inglesa dentro de um período de tempo bem menor.

\section{Considerações finais}

Com o presente estudo foi possível observar que a prática anglocêntrica prevalece não só na tradução de aspectos culturais desconhecidos para 0 leitor. A tendência a neutralizar o estranhamento é comum até mesmo no

\footnotetext{
${ }^{6}$ Although ethnocentric discursive strategies may endow a translation with a nationalistic effect, they can never entirely remove the foreignness of a foreign text. Cultural difference will still be communicated on other textual levels, both formal and thematic, insofar as they deviate noticeably from cultural works and traditions in the receiving language.
} 
REBECHI, R. R. 'Cachaça' na tradução de obras literárias brasileiras

para a língua inglesa

caso de palavras estrangeiras já dicionarizadas em língua inglesa, que são, frequentemente, assimiladas pela cultura de chegada por meio de outras com as quais os leitores estão mais familiarizados, aumentando, assim sua inteligibilidade. 0 resultado dessa prática recorrente exercida pela cultura dominante acaba acarretando o apagamento de marcas culturais da cultura de partida.

\section{Referências bibliográficas}

Amado, J. D. Flor e seus dois maridos. São Paulo: Martins, 1971.

AuberT, F. H. Modalidades de tradução: teoria e resultados. TradTerm, São Paulo, v. 5, n. 1, 1998. p. 99-128.

Azevedo, A. O Cortiço. São Paulo: Ática, 1890.

. The slum: a novel. Tradução David Rosenthal. New York: Oxford, 2000. . O Mulato. S. I.: Ática, 1881.

. Mulatto. Tradução Graeme MacNicoll. Cranbury: Associated University Presses, 1990.

BURKE, P. Cultures of translation in early modern Europe. In: BURKE, P.; HSIA, R. P. (ed.) Cultural translation in early modern Europe. Cambridge: Cambridge University Press, 2008.

CAMBRIDGE International Dictionary of English. Cambridge: Cambridge University Press, 1995.

CORRÊA, R. H. M. A. et al. Bahia com pimenta: um estudo comparado da tradução da culinária de $\mathrm{D}$. Flor para o francês, o inglês e o espanhol. Terra Roxa e Outras Terras, v. 3, 2003. Disponível em: «ttp:// www. uel. br/ pos/letras/ terraroxa/g pdf/ vol3/ vol3 df. pdf $>$. Acesso em: 27 jul. 2011.

CostA, A. T. P. Brasil mostrando a sua cara: estratégias de tradução no material de divulgação cultural - um estudo baseado em corpus. Dissertação (Mestrado em Linguística Aplicada)-Departamento de Línguas Estrangeiras e Tradução, Universidade de Brasília, Brasília: 2006.

De La TallLe, Y. Moral e ética: dimensões intelectuais e afetivas. Porto Alegre: Artmed, 2006. 
REBECHI, R. R. 'Cachaça' na tradução de obras literárias brasileiras

para a língua inglesa

DeRRIDA, J. What is a "relevant" translation? Tradução Olivia Niemeyer Santos. ALFA, v. 44, n.esp.,2000. p. 13-44.

DourADo, A. Os sinos da agonia. Rio de J aneiro: Expressão e Cultura, 1975. . The bells of agony. Tradução J ohn Parker. London: Peter Owen, 1988.

HATIM, B.; MASON, I. The translator as communicator. London-New York: Routledge, 1997.

HSIA, R. P. The Catholic mission and translations in China, 1583-1700. In: BURKE, P.; HSIA, R. P. (ed.) Cultural translation in early modern Europe. Cambridge: Cambridge University Press, 2008.

LefEVERE, A. (ed.). Translating literature: the German tradition from Luther to Rosenzweig. Assen: Van Gorcum, 1997.

LÉVI-STRauss, C. The culinary triangle. In: Counihan, C. Food and culture: a reader. New York: Routledge, 2007. p. 28-35.

MACMILLAN English Dictionary for Advanced Learners of American English. Oxford: Macmillan Education, 2002.

Mello; G. G.; Vollet, N. A ética e o pós-colonialismo: uma prática de tradução. ALFA, v. 44, n. esp. Universidade Estadual Paulista, UNESP, 2000.

PYM, A. Pour une éthique du traducteur. Arras: Artois Presses Université, Ottawa; Presses de l'Université d'Ottawa, 1997.

REBECHI, R. R. A imagem do brasileiro no discurso do norte-americano em livros de culinária brasileira. Dissertação (Mestrado em Letras)Faculdade de Filosofia, Letras e Ciências Humanas, Universidade de São Paulo, São Paulo, 2010.

REY, M. Memórias de um gigolô. São Paulo: Ática, 1986.

. Memoirs of a gigolo. Tradução Clifford Landers. New York: Avon, 1987.

SCHLEIERMACHER, F. Sobre os diferentes métodos de tradução. In: HeIDERMANN, W. (org.) Clássicos da teoria da tradução. Florianópolis, NUT, 2a. ed., vol. 1. 2010. p. 38-101.

SOARES, J. O xangô de Baker street. São Paulo: Companhia das Letras, 1995.

A samba for Sherlock. Tradução Clifford Landers. New York: Vintage, 1997.

VeNUTI, L. The translator's invisibility: a history of translation. London-New York: Routledge, 1995.

. The scandals of translation: towards an ethics of difference. LondonNew York: Routledge, 1998. 
REBECHI, R. R. 'Cachaça' na tradução de obras literárias brasileiras

para a língua inglesa

. Local Contingencies: Translation and National Identities. In: Bermann, S.; Wood, M. (ed.) Nation, language and the ethics of translation. Princeton e Oxford: Princeton University Press, 2005.

White, J. B. On the virtues of not understanding. In: Dinguaney, A; Maier, C. Between languages and cultures. Pittsburgh e Londres: University of Pittsburgh Press, 1995. 